\title{
American trypanosomiasis (Chagas' disease): an unrecognised cause of stroke
}

\author{
F J Carod-Artal, A P Vargas, M Melo, T A Horan
}

J Neurol Neurosurg Psychiatry 2003;74:516-518

Background: American trypanosomiasis, known as Chagas' disease $(C D)$ is a major cause of cardiomyopathy in South America. Irreversible damage to the heart can appear 10 to 20 years after chagasic infection. The frequency of cerebrovascular complications in chronic CD is unknown.

Objectives: To describe a group of patients with chronic or latent $C D$ affected by ischaemic stroke and identify predictive variables for stroke in $C D$ patients.

Patients and methods: Retrospective case series of stroke patients with $C D$ was studied using a cross sectional, descriptive design. CD was confirmed by positive immunofluorescence and haemaglutination serology. Data were collected on age, sex, vascular risk factors, previous history of $C D$, diagnostic stroke subtype, electrocardiograph and echocardiography findings. Frequency of vascular risk factors were compared with a control group of 239 non-chagasic stroke patients.

Results: 136 consecutive CD stroke patients, mean age 56 years, 72 women and 64 men were identified. Vascular risk factors were observed in $81.6 \%$ of $C D$ patients. Hypertension $(70.29 \%$ versus $51.47 \%$; $p=0.0004)$, diabetes mellitus (15.9\% versus $6.61 \% ; p=0.0143)$, and tobacco use $(53.98 \%$ versus $30.88 \%$; $p=0.00002)$ were significantly less frequent in the CD stroke group. Cardiomyopathy was significantly higher in $C D$ stroke patients (45.58\% versus $24.69 \%$; $p=0.00005)$. Abnormal electrocardiograms was observed in $82 \%$ of chagasic patients (right bundle branch block $39.5 \%$, left anterior fascicular block 35.8\%). Left ventricle (LV) diastolic dysfunction (61.47\%), LV systolic dysfunction (51.18\%), congestive cardiomyopathy $(29.92 \%)$, and apical aneurysm $(15.74 \%)$ were the most frequent echocardiographic findings. Aetiologies were cardioembolism $(52.2 \%)$, undetermined $(36.76 \%)$, atherothrombotic $(8.82 \%)$, and small vessel stroke $(2.2 \%)$. A diagnosis of $C D$ was established after presentation with stroke in $38.23 \%$ of the patients.

Conclusions: $C D$ should be included in the differential diagnosis of stroke in patients of South American origin.

A merican trypanosomiasis, Chagas' disease (CD) is an important public health problem and a major cause of cardiomyopathy in South America. The causative organism Trypanosoma cruzi, is widespread throughout South and Central America, extending to southern Texas. ${ }^{12}$ Sixteen to eighteen million people have chronic infection resulting in 50000 deaths each year. Although up to $8 \%$ of the population in South America is seropositive, only $10 \%$ to $30 \%$ of these will develop symptomatic disease. The emigration of millions of people from countries where $T$ cruzi is endemic to developed countries has increased the risk of unsuspected $C D$, and transfusion transmitted $T$ cruzi. ${ }^{34}$
Irreversible cardiac damage can appear 10 to 20 years after chagasic infection. The principal manifestations of chagasic heart disease are cardiac dilatation, heart failure, arrhythmia, and cardiac arrest. ${ }^{56}$ Cardiac diseases increase the risk for occurrence of ischaemic stroke. ${ }^{7}$ The clinical frequency of cerebrovascular complications in $\mathrm{CD}$ has not been previously described, although postmortem studies have shown that $9 \%-36 \%$ of patients with Chagas' cardiomyopathy have evidence of a cerebral infarction..$^{8-10}$ The identification and control of cardioembolic stroke risk factors is the cornerstone of the stroke prevention strategies in $\mathrm{CD} .^{11}$

The objective of our study was to analyse the importance of chronic CD as a cause of ischaemic stroke in a Brazilian population. Associated vascular risk factors (VRFs) were analysed to identify the variables that could predict stroke in both the chronic or latent forms of CD. Heightening awareness of any such important relation might also lead to consideration of the diagnosis of previously undetected cases of CD in at risk populations with ischaemic stroke.

\section{METHODS}

We included in this study all patients admitted to the Departments of Neurology and Rehabilitation at Sarah Hospital, in Brasilia DF, Brazil, between January 1999 and July 2001 with the clinical diagnose of ischaemic stroke and positive chagasic serology. We defined the presence of CD in a stroke patient when both immunofluorescence and haemaglutination were positive. Only stroke patients with the chronic or latent CD were included in the study group.

Diagnosis of stroke was confirmed by clinical and/or radiological findings according to Stroke Data Bank criteria. ${ }^{12}$ We adopted the criteria for classification of acute ischaemic stroke subtype used in the multicentre clinical ORG 10172 Trial in Acute Stroke Treatment (TOAST). ${ }^{13}$ The Oxfordshire classification ${ }^{14}$ was used to define stroke location.

Demographic variables included age, sex, previous history of stroke, patient awareness of a history of CD, family history of $\mathrm{CD}$, and the patient's region of origin. Data collected included VRFs, location of brain lesion, diagnostic stroke subtype, electrocardiograph and echocardiography findings. All patients underwent electrocardiography, echocardiogram, chest radiograph, and brain computed tomography. Further ancillary studies analysed were brain magnetic resonance imaging (22\% patients), carotid Doppler $(72.8 \%)$, and transcranial Doppler ( 37\%).

A cross sectional, descriptive analysis design was developed. Collected data on VRFs were compared with a control group of non-chagasic stroke patients. StatView 4.02 for Macintosh was used to obtain descriptive statistics, Fisher's exact test, $\chi^{2}$ test, and analysis of variance measurements. A two tailed probability value of less than 0.05 was considered statistically significant.

Abbreviations: $C D$, Chagas' disease; VRF, vascular risk factor; LV, left ventricle 


\begin{tabular}{|c|c|c|c|}
\hline Variable & $\begin{array}{l}\text { CD patients } \\
\text { (\%) } n=136\end{array}$ & $\begin{array}{l}\text { Non-chagasic } \\
\text { patients }(\%) \\
n=239\end{array}$ & $\mathrm{p}$ Value \\
\hline Age (y) & 56 & 57.4 & \\
\hline Sex, male & 47 & 56.48 & \\
\hline Hypertension & 51.47 & 70.29 & 0.0004 \\
\hline Clinical cardiopathy & 45.59 & 24.69 & 0.0005 \\
\hline congestive heart failure & 31.62 & & \\
\hline Cardiac arrhythmia & 23.53 & & \\
\hline pacemaker & 10.29 & & \\
\hline atrial fibrillation & 11 & & \\
\hline AV block & 2.20 & & \\
\hline ischaemic heart disease & 4.41 & & \\
\hline valvular heart disease & 2.94 & & \\
\hline $\begin{array}{l}\text { Smoking } \\
\text { ex smoker }\end{array}$ & $\begin{array}{l}30.88 \\
15.44\end{array}$ & 53.98 & 0.0002 \\
\hline Hyperlipidaemia & 27.94 & 30.95 & n.s \\
\hline Previous stroke & 22 & 13.81 & 0.055 \\
\hline Diabetes & 6.62 & 15.9 & 0.0143 \\
\hline Peripheral embolic disease & 2.20 & & \\
\hline
\end{tabular}

\section{RESULTS}

A total of 966 stroke patients (432 women, 534 men; mean age of 58.5 years) were admitted from January 1999 to July 2001. Serological results for CD were availiable in 557 patients; $24.4 \%$ of these patients ( 136 patients) had a positive chagasic serology. These 136 study group patients consisted of 72 women (53\%) and 64 men (47\%) with a mean age of 56 years, ranging from 17 to 85 . Sixty nine per cent were younger than 65. The diagnosis of CD was established only after stroke in $38 \%$ of study patients. Similarly, one third of stroke patients without known VRFs ( 8 of 24) had CD diagnosed after their strokes. A family history of CD existed in $38 \%$ of patients. A chronic intestinal form was identified in $20 \%$ of the patients (megaesophagus $8 \%$, megacolon $8 \%$, and both $4 \%$ ).

Chest radiography demonstrated abnormalities in 33\% of patients, chiefly cardiomegaly. A carotid Doppler was done in $74 \%$ of patients, of which $63 \%$ were normal, $24 \%$ showed atheromatous plaques at the bifurcation, $11 \%$ had carotid thrombosis, and $2 \%$ patients had stenosis higher than $50 \%$. Vascular epilepsy developed during follow up in $14 \%$.

\section{Vascular risk factors}

Frequency of VRFs in chagasic stroke patients were compared with a control group of 239 non-chagasic stroke patients ( 104 women and 135 men with a mean age of 57.4 years). Ethnicity of both groups was indistinguishable. Significantly higher frequencies of hypertension, diabetes mellitus, and tobacco use existed in the non-CD stroke group. Prior stroke and cardiomyopathy were significantly higher in the chagasic stroke group (table 1 ).

\section{Electrocardiograph and echocardiograph abnormalities}

Electrocardiograph abnormalities occurred in $82 \%$ of CD patients. A right bundle branch block was observed in 39.5\%, followed in frequency by left anterior fascicular block (36\%). Of the 67 patients undergoing Holter monitoring 48 patients (72\%) showed frequent ventricular extra systoles. Altogether 127 patients (94\%) underwent an echocardiogram, either transthoracic alone $(63 \%)$, transoesophageal alone $(0.7 \%)$, or both $(30 \%)$. A normal echocardiogram was obtained in 21 patients $(17 \%)$. Echocardiograms were not obtained in eight, of which two had failed because of an inadequate thoracic window. Left ventricular diastolic dysfunction (LVD) was the most frequent echocardiography finding. Apical aneurysm occurred in $16 \%$. It was more frequent among younger chagasic stroke patients (mean 52 years) and in those without VRFs (26\%).
Table 2 Stroke characteristics in the CD stroke population

\begin{tabular}{lll}
\hline & Number & $\%$ \\
\hline Aetiology of stroke & & \\
cardioembolism & 71 & 52.21 \\
stroke of undetermined cause & 50 & 36.76 \\
small vessel occlusion & 3 & 2.20 \\
large artery atherosclerosis & 12 & 8.83 \\
Stroke syndrome & & \\
TACl & 65 & 47.79 \\
PACl & 51 & 37.50 \\
POCl & 13 & 9.56 \\
LACl & 7 & 5.15 \\
Vascular territory & & \\
right MCA & 51 & 37.50 \\
left MCA & 46 & 33.82 \\
base ganglia/internal capsule & 19 & 15.44 \\
semiovale centre & 5 & 3.68 \\
top of the basilar syndrome & 4 & 2.94 \\
pons & 4 & 2.94 \\
PCA & 3 & 2.21 \\
cerebellum & 2 & 1.47 \\
Previous stroke (n=30 patients) & & \\
same vascular territory & 11 & 36.66 \\
different vascular territory & 19 & 63.33 \\
right MCA & 4 & 13.33 \\
left MCA & 11 & 36.67 \\
PCA & 4 & 13.33 \\
pons & 5 & 16.66 \\
base ganglia & 5 & 16.66 \\
Silent infarction (n=25 patients) & 12 & 48 \\
lenticuloestriates & 5 & 20 \\
pons & 3 & 12 \\
cerebellum & 2 & 8 \\
MCA & 1 & 8 \\
PCA & & 4 \\
leucoaraiose & & \\
\hline & & \\
\hline
\end{tabular}

$\mathrm{TACl}$, total anterior circulation infarction; $\mathrm{PACl}$, partial anterior circulation infarction; $\mathrm{POCl}$, posterior circulation infarction; $\mathrm{LACl}$, lacunar circulation infarction; MCA, middle cerebral artery; PCA, posterior cerebral artery.

There were no statistical differences in age or sex of the CD stroke patients with cardiovascular disease including chagasic apical aneurysm, LVD, bundle block, hypertension, ischaemic cardiomyopathy, and heart failure. Dilated cardiomyopathy when present occurred at a significantly younger age (mean age 51 versus 58 years; $p=0.012$ ). A prior history of chagasic stroke was not related to the presence of VRFs, nor the presence of arrhythmias.

\section{Stroke characteristics}

According to TOAST criteria, we defined 52\% of CD stroke patients as cardioembolism (with an obvious source of embolus ), $9 \%$ as atherothrombotic stroke, $2 \%$ as small vessel stroke, and $37 \%$ as stroke of undetermined cause (table 2 ). In this last group we also included stroke patients with normal carotid Doppler, presence of hypertension, and findings on echochardiograph such as LVD. Middle cerebral artery was the most frequently affected vascular territory $(71 \%)$, followed by basal ganglia or internal capsule infarctions (15\%). Silent infarctions were observed in 25 patients. Strokes in the territory of the lenticuloestriate arteries were the most frequent ischaemic area in those with silent infarctions.

\section{DISCUSSION}

Affecting 30\% of patients, chronic cardiomyopathy is the most common clinical form of CD. Its onset averages 30 years after initial infection. ${ }^{15}{ }^{16} \mathrm{CD}$ cardiomyopathy is characterised by congestive heart failure, sudden cardiac death, intraventricular conduction defects, arrhythmias, and thromboembolism. ${ }^{17-22}$ Chagasic embolic stroke is clinically indistinguishable from other aetiologies. ${ }^{23}$ 
Three areas of particular interest were identified in our patients. Firstly, the high frequency of prior ischaemic stroke $(22 \%)$ noted in our CD stroke patients. Secondly, the higher frequency of cardiopathy in the CD stroke group compared with non-chagasic stroke. Thus prevention of subsequent stroke by long term anticoagulation would seem indicated when chagasic cardiomyopathy is evident in stroke patients. Postmortem studies have shown cerebral infarction in $9 \%-36 \%$ of patients with CD cardiomyopathy. ${ }^{8-10}$ Therefore there may be a need for primary prevention in all patients with CD cardiomyopathy.

Thirdly, the high frequency (19\% CD) of stroke patients without any evident VRFs. Some $37 \%$ of CD stroke patients of undetermined cause had normal echocardiograms, normal carotid Doppler, and no associated VRFs. Undetected nonchagasic cardiovascular disease might account for this finding. However, the remaining $63.3 \%$ of CD stroke patients of undetermined cause typically had only one associated VRF, usually hypertension or LVD. Thus it seems that the paucity of VRFs in this group may indicate the existence of other possible mechanisms.

Acting similarly to vasculitis active in the pathogenesis of chagasic cardiomyopathy, the recently reported cerebral vasculitis in $\mathrm{CD}$ patients ${ }^{24}$ may explain this previously unappreciated phenomenon. T cruzi infection of the myocardium activates extra cellular signal regulated kinase, activator protein- 1 , endothelin- 1 , and cyclins. ${ }^{24}$ This possible aetiological mechanism may call for study of anticoagulation in chagasic patients with stroke even in the absence of VRFs.

An additional $26 \%$ of patients without VRFs presented with an apical aneurysm. Asymptomatic apical aneurysm could play a part in the aetiology of stroke in these patients who, otherwise, presented no clinical symptoms of cardiopathy.

We did not specifically study haemorrhagic strokes in patients with $\mathrm{CD}$. The relation of Chagas' vasculitis to the occurrence of stroke should be further studied in view of the disproportionately high rate of stroke of undetermined cause in CD. Longitudinal studies of VRFs are needed to quantify recurrence risk and long term mortality after chagasic stroke. Why seropositive patients without VRFs develop stroke may be related to the function of procoagulant factors, such as anticardiolipin, drepanocytosis or C, S protein deficiencies.

The WHO control measures initiated against the domiciliary vector responsible for $T$ cruzi transmission has had a dramatic effect in reducing new cases of CD in the Cone of South America. However, the long latent period before the chronic stage will maintain CD as an important public health problem for decades. The inclusion of CD in the differential diagnosis of stroke in patients of South American origin is important in the recognition, and prevention of further CD complications.

\section{Authors' affiliations \\ F J Carod-Artal, A P Vargas, M Melo, T A Horan, Neurology Department, Sarah Hospital, Brasilia, Brazil}

Competing interests: none declared.
Correspondence to: Dr F J Carod-Artal, Neurology Department, Sarah Hospital, SMHS quadra 501, conjuntoA, Brasilia, Brazil 70330-150; fjcarod@aol.com

Received 24 July 2002

Accepted in revised form 16 November 2002

\section{REFERENCES}

1 Kirchoff LV. Trypanosoma species (American Trypanosomiasis, Chagas' disease): biology of trypanosomes. In: Mandell GL, Bennett JE, Dolin R, eds. Principles and practice of infectious disease. New York: Churchill Livingstone, 1995:2442-50.

2 Cegielsk JP, Durack DT. Trypanosomiasis. In: Scheld WM, Whitley RJ, Durack DT, eds. Infections of central nervous system. Philadelphia: Lippincott-Raven 1997:807-29.

3 Kirchoff LV. American trypanosomiasis (Chagas' disease): a tropical disease now in the United States. N Engl J Med 1993;329:639-44.

4 Leiby DA, Rentas FJ, Nelson KE, et al. Evidence of Trypanosoma cruzi infection (Chagas' disease) among patients undergoing cardiac surgery. Circulation 2000;102:2978-82.

5 Rassi A Jr, Rassi A, Little WC. Chagas' heart disease. Clin Cardiol 2000;23:883-9.

6 Umezawa ES, Stolf AMS, Corbett CEP, et al. Chagas' disease. Lancet 2001;357:797-9.

7 Sacco RL. Risk factors, outcomes, and stroke subtypes for ischemic stroke. Neurology 1997;49 (suppl 4):39-44.

8 Pitella JE, Meneguette C, Barbosa AJ. Histopathological and immunohistochemical study of the brain and heart in the chronic cardiac form of Chagas' disease. Arq Neuropsiquiatr 1993;51:8-15.

9 de Queiroz AC. Estudo anatomopatológico do encéfalo na forma crónica da doença de Chagas. Rev Pat Trop 1978:7:134-45.

10 Pitella JE. Ischemic cerebral changes in the chronic chagasic cardiopathy. Arq Neuropsiquiatr 1984;42:105-15.

11 Carod Artal FJ, Melo M, Vargas AP. Ictus cardioembólico en la enfermedad de Chagas. Rev Neurol 2001;33:311-15.

12 Foulkes MA, Wolf PA, Price TR, et al. The Stroke Data Bank: design, methods, and baseline characteristics. Stroke 1988;19:547-54.

13 Adams HP Jr, Bendixen BH, Kapelle L, et al. Classification of subtype of acute ischemic stroke: definitions for use in a multicenter clinical trial. Stroke 1993;24:35-41.

14 Bamford J, Sandercock P, Dennis M, et al. Classification and natural history of clinically identifiable subtypes of cerebral infarction. Lancet 1991;337:1521-6

15 Ianni BM, Mady C, Arteaga E, et al. Doenças cardiovasculares observadas durante o seguimento de um grupo de pacientes na forma indeterminada da doença de Chagas. Arq Bras Cardiol 1998;71:21-4.

16 Betestti RB, Rossi MA. A rational approach for mortality risk stratification in Chagas' heart disease. Int J Cardiol 1997;58:199-209.

17 Arteaga-Fernandez E, Baretto ACP, lanni BM, et al. Trombose cardíaca e embolia em pacientes falecidos de cardiopatia chagásica crónica. Arq Bras Cardiol 1989;52:189-92.

18 Barretto AC, Mady C, lanni BM, et al. Relação entre arritmia ventricular e função cardiaca na doença de Chagas. Arq Bras Cardiol 1995;64:533-5.

19 Oliveira JSM, Araujo RLC, Navarro MA, et al. Cardiac thrombosis and trhomboembolism in chronic Chagas' heart disease. Am J Cardiol 1983;2:147-51.

20 Bestetti R. Stroke in a hospital-derived cohort of patients with chronic Chagas' disease. Acta Cardiol 2000;55:33-8.

21 Albanesi-Filho FM, Gomes Filho JB. Thromboembolism in patients with apical lesion caused by chronic chagasic cardiopathy. Rev Port Cardiol $1991 ; 10: 35-42$

22 Mady C, Cardoso RH, Barretto AC, et al. Survival and predictors of survival in patients with congestive heart failure due to Chagas' cardiomyopathy. Circulation 1994;90:3098-102.

23 Rey RC, Monteverde DA, Sicca RE. Cardiac sources of cerebral embolism. Arch Neurol 1991;48:359-60.

24 Petkova SB, Huang H, Factor SM, et al. The role of endothelin in the pathogenesis of Chagas' disease. Int J Parasitol 2001;31:499-511. 